\title{
Characteristics of Patients with Tuberculous Pleural Effusion in Rural Nepal
}

\author{
MS Paudel, ,a,c Anjana Kafle,, Bishal KC, a,c Sahadev Prashad Dhungana, ${ }^{\mathrm{a}, \mathrm{c}}$ \\ Anuj Poudel, a,e Shamsuddinn ${ }^{\mathrm{a}, \mathrm{c}}$
}

\begin{abstract}
:
Introduction: Tuberculosis (TB) is a major cause of mortality and morbidity in developing countries. Tubercular Pleural effusion is the second most common form of extra pulmonary tuberculosis (EPTB), superseded in Prevalence only by lymph node tuberculosis. Pleural effusion occurs in approximately $5 \%$ of patients with TB. The purpose of this study was to assess the demographic characteristics of patients presenting with pleural effusion in rural Nepal. Methods: A retrospective study was conducted with all the cases diagnosed and admitted with pleural effusion at Lumbini Medical College And Teaching Hospital from April 2011 to March 2013 of all the cases diagnosed and admitted with pleural effusion were included in the study. Hundred cases diagnosed with pleural effusion by clinical Examination or chest X-ray or ultrasonography's (USG) of the chest were included in the studied. The following parameters patients demographic profile, causes of pleural effusion, location (unilateral/bilateral), hemoglobin and complete blood count, sputum stain and culture sensitivity, Monteux test, chest X-ray and USG findings and Pleural fluid analysis (biochemical, hematological, microbiological and cytological) were analyzed by using SPSS 21. Results: Out of 100 cases, the cause of pleural effusion in 59 patients was tuberculosis, 14 by malignancy, next 14 by Para pneumonic Effusion, 12 by congestive cardiac failure and three cases by alcoholic liver disease. Patients with tuberculous pleural effusion were younger, predominantly males, had unilateral effusion, lower blood hemoglobin, lower Pleural fluid neutrophils, higher pleural fluid Adenosine Deaminase (ADA) levels and higher level of pleural fluid to serum protein ratio as compared to the patients with non-tuberculous effusion. Conclusion: Tuberculosis is the most common cause of pleural effusion in patients of rural Nepal.
\end{abstract}

Keywords: adenosine $\bullet$ deaminase $\bullet$ extrapulmonary $\bullet$ exudative $\bullet$ malignancy

\section{INTRODUCTION:}

Tuberculosis(TB) is amajorcause of mortality and morbidity in developing countries. Tuberculous pleural effusion is the second most common form of extrapulmonary tuberculosis(EPTB), superseded in

\footnotetext{
a - Lecturer

b - Medical Officer

c - Department of Medicine, Lumbini Medical College Teaching Hospital

d - Department of OBG, Lumbini Medical College Teaching Hospital

e - Department of Pathology, Lumbini Medical College Teaching Hospital
}

Corresponding Author:

Dr. Anjana Kafle

e-mail:kafle_anjana@hotmail.com

How to cite this article:

Paudel MS, Kafle A, Chettri BK, Dhungana SP, Poudel A, Shamsuddin. Characteristics of patients with tuberculous pleural effusion in rural Nepal. Journal of Lumbini Medical College. 2013;1(1):31-4. doi:10.22502/jlmc.vli1.10. prevalence only by lymph node tuberculosis. Pleural effusion occurs in approximately $5 \%$ of patients with TB. ${ }^{1}$ The incidence of EPTB is rising with the rise in pandemic of human immunodeficiency virus (HIV). The diagnosis of tuberculous pleural effusion is difficult as extrapulmonary specimens have very few bacilli and consequently are associated with low sensitivity of acid fast bacillus (AFB) smear and culture. Pleural effusions are classified into transudative or exudative. ${ }^{2,3}$ Exudative pleural effusions require further evaluation to differentiate among tuberculosis, malignancy and para pneumonic effusion which are the major causes in patients. ${ }^{4-6}$

\section{METHODS:}

This retrospective study was carried out 
in patients over the age of 14 years, admitted to the medical ward at Lumbini Medical College and Teaching Hospital (LMCTH), Palpa, from April 2011 to March 2013. All patients who were admitted with a diagnosis of pleural effusion were included. The study was approved by the Institutional Review Committee. Data was retrieved from the medical record section. Information on regarding the diagnosis, comorbidities and results of biochemical analysis of blood and pleural fluid was noted. Patients were classified as having effusion due to tuberculosis, malignancy, pneumonia, congestive cardiac failure or liver disease. Rests of the causes were classified as others. Data were also obtained regarding sputum examination and pleural fluid cytology in all patients. Results were analyzed using Statistical Package for Social Sciences (SPSS 21). Continuous data were expressed as mean, standard deviation (SD), median and interquartile range (IQR), and a categorical variable as number (\%). In case of continuous variables, t-test/Mann-Whitney test was applied as appropriate to see the difference in average between the groups. Similarly, Chi square analysis was performed to test differences in proportions of categorical variables between two or more groups. The cut-off value for significance was considered to be $\mathrm{p}<0.05$.

\section{RESULTS:}

One hundred patients were included in the study. Fifty nine patients were diagnosed as tuberculous pleural effusion, 14 had malignant pleural effusion, 14 had parapneumonic effusion, 10 had effusion due to congestive cardiac failure and three had liver disease. The patients were divided into two groups. More than $50 \%$ of cases were diagnosed as tuberculous pleural effusion $(n=59)$ whereas 41 cases were under non-tuberculous pleural effusion.

Table 1 shows that the patients with tuberculous effusion were younger than the patients with non-tuberculous pleural effusion $(p=0.03)$. Patients with tuberculous pleural effusion were more commonly males $(\mathrm{p}=0.04)$, had lower levels of hemoglobin $(p=0.01)$ and the effusion was more commonly unilateral $(0.001)$ as compared to the patients with non-tuberculous pleural effusion. Pleural fluid analysis was also significantly different between the two groups with patients with tuberculous pleural effusion having higher pleural fluid level of adenosine deaminase (ADA) $(p=0.001)$, higher differential lymphocyte count $(p=0.04)$, lower differential neutrophil count $(\mathrm{p}=0.02)$, higher pleural fluid lymphocytes to neutrophils ratio $(p=0.02)$ and higher pleural fluid to serum protein ratio $(p=0.006)$.

Table 1: Comparison between tuberculous and non-tuberculous pleural effusion

\begin{tabular}{|c|c|c|c|}
\hline Characteristics & $\begin{array}{l}\text { Tuberculous pleural effu- } \\
\qquad \operatorname{sion}(n=59)\end{array}$ & $\begin{array}{c}\text { Non-tuberculous pleural } \\
\text { effusion }(n=41)\end{array}$ & p-value \\
\hline Age (years) & $57.2 \pm 15.94$ & $64.7 \pm 16.32$ & 0.03 \\
\hline Gender & $\begin{array}{l}\text { Male }=46(77.9 \%) \\
\text { Female }=13(22.0 \%)\end{array}$ & $\begin{array}{l}\text { Male }=24(58.5 \%) \\
\text { Female }=17(41.4 \%)\end{array}$ & 0.04 \\
\hline Duration of illness (days) & $18.9 \pm 14.09$ & $19.5 \pm 18.54$ & 0.41 \\
\hline Laterality of effusion & $\begin{array}{l}\text { Unilateral }=57(96.6 \%) \\
\text { Bilateral }=2(3.3 \%)\end{array}$ & $\begin{array}{l}\text { Unilateral=30(73.1\%) } \\
\text { Bilateral=11(26.8\%) }\end{array}$ & 0.001 \\
\hline Hemoglobin (g/dl) & $10.8 \pm 1.60$ & $11.5 \pm 1.65$ & 0.01 \\
\hline Blood glucose (mg/dl) & $113 \pm 40.46$ & $129.6 \pm 160.9$ & 0.28 \\
\hline AST (U/L) & $54.6 \pm 29.63$ & $51.1 \pm 71.41$ & 0.64 \\
\hline $\operatorname{ALT}(U / L)$ & $50.5 \pm 29.63$ & $62.1 \pm 67.39$ & 0.10 \\
\hline Serum protein (g/dl) & $6.6 \pm 0.51$ & $6.7 \pm 0.46$ & 0.26 \\
\hline Creatinine $(\mathrm{mg} / \mathrm{dl}$ & $0.9 \pm 0.21$ & $0.9 \pm 0.17$ & 0.48 \\
\hline Pleural fluid TLC ( /cu.mm) & $1220 \pm 2419$ & $907 \pm 1223$ & 0.31 \\
\hline Pleural fluid neutrophils (\%) & $22.0 \pm 26.54$ & $34.4 \pm 34.10$ & 0.02 \\
\hline Pleural fluid Iymphocytes (\%) & $76.5 \pm 27.44$ & $65.6 \pm 33.72$ & 0.04 \\
\hline Pleural fluid lymphocytes/ neutrophil ratio & $16.4 \pm 23.00$ & $8.5 \pm 11.12$ & 0.02 \\
\hline Pleural fluid glucose (mg/dl) & $82.5 \pm 36.69$ & $92.2 \pm 35.8$ & 0.19 \\
\hline Pleural fluid ADA (U/L) & $53.9 \pm 22.52$ & $15.0 \pm 7.72$ & 0.0001 \\
\hline Pleural fluid/serum protein & $0.6 \pm 0.12$ & $0.5 \pm 0.20$ & 0.006 \\
\hline
\end{tabular}

AST=Aspartate amino transferase, ALT=Alanine amino transferase, TLC=total leukocyte count, $A D A=$ adenosine deaminase 
The most common symptoms presented in patients with tuberculous pleural effusion were cough $(54.2 \%)$, fever $(50.1 \%)$ and shortness of breath $(38.9 \%)$. In patients with malignant pleural effusion, most common symptom was weight loss $(100 \%)$ whereas cough was most common symptom in patients with parapneumonic effusion (Table 2). Only four $(6.7 \%)$ patients with tuberculous pleural effusion had sputum positive for acid fast bacillus (AFB) and none had AFB stain positive in the pleural fluid. Twenty eight percent of patients with tuberculous pleural effusion had chronic obstructive pulmonary disease (COPD) and $16.9 \%$ had diabetes mellitus (DM). While, $42.8 \%$ of patients with malignancy had underlying COPD and $21.4 \%$ had DM (Table 3).

\section{DISCUSSION:}

This is a retrospective study evaluating the etiology of pleural effusion in patients of rural Nepal. Tuberculosis was identified as the most common cause of pleural effusion and it resulted most commonly into a unilateral pleural effusion. As compared to the patients with non tuberculous effusion, patients with tuberculous effusion were younger, more commonly males, had higher levels of lymphocytes, lower levels of neutrophils, higher level of lymphocyte to neutrophil ratio and higher levels of ADA in pleural fluid. The ratio of pleural fluid to serum protein was higher in patients with tubercular effusion. Coughs, fever, shortness of breath and chest pain were the major presenting complains of patient with tubercular effusion. COPD and DM were the major comorbidities in this group of patients. Only four patients with tuberculous pleural effusion had sputum positive pulmonary tuberculosis.

Of all the causes of pleural effusion, tuberculosis is identified as the most common cause in many studies. ${ }^{7,8,10,11}$ In a retrospective study from Malaysia, the most common cause of pleural effusion was tuberculosis and $70.4 \%$ of patients in this study were males. ${ }^{9}$ Tuberculosis is also more common in younger patients and malignancy is the important cause of pleural effusion in older patients. ${ }^{9-11}$ These results are similar to that observed in this study.

Increased level of lymphocytes was seen in tubercular pleural effusion in various studies. ${ }^{12,13}$ Adenosine deaminase (ADA) level $>36 \mathrm{U} / 1$ is seen in patients with tuberculosis and level $>100 \mathrm{U} / 1$ is not see in other causes of pleural effusion. ${ }^{14} \mathrm{~A}$ combined use of pleural fluid ADA level of 50U/L with lymphocyte/neutrophil ratio of 0.75 or greater has been shown to have increased specificity for diagnosis of tubercular pleurisy. ${ }^{15}$ Our patients with tubercular pleural effusion had mean ADA level of 53.9U/L and mean lymphocyte to neutrophil ratio of 16. In 1972, pleural fluid to serum protein ratio of

Table 2: Symptoms at presentation in patients with pleural effusion $(N=100)$

\begin{tabular}{|l|c|c|c|c|c|c|c|}
\hline \multicolumn{1}{|c|}{ Diagnosis } & Cough $\mathbf{f ( \% )}$ & $\begin{array}{c}\text { Shortness } \\
\text { of breath } \\
\mathbf{f ( \% )}\end{array}$ & $\begin{array}{c}\text { Chest } \\
\text { pain } \mathbf{f}(\%)\end{array}$ & Fever f(\%) & $\begin{array}{c}\text { Weight } \\
\text { loss f(\%) }\end{array}$ & $\begin{array}{c}\text { Edema } \\
\mathbf{f}(\%)\end{array}$ & $\begin{array}{c}\text { Others } \\
\mathbf{f}(\%)\end{array}$ \\
\hline Tuberculosis & $32(54.2)$ & $23(38.9)$ & $20(33.8)$ & $29(50.1)$ & $13(22.0)$ & $2(3.3)$ & $2(3.3)$ \\
\hline Malignancy & $13(92.8)$ & 0 & 0 & $3(21.4)$ & $14(100)$ & 0 & $1(7.1)$ \\
\hline Pneumonia & $12(85.7)$ & $5(35.7)$ & $3(21.4)$ & $10(71.4)$ & $1(7.1)$ & $3(21.4)$ & 0 \\
\hline Congestive cardiac failure & $1(10)$ & $4(40)$ & 0 & 0 & $1(10)$ & $7(70)$ & $4(40)$ \\
\hline Liver disease & 0 & 0 & 0 & 0 & 0 & $3(100)$ & $2(66.6)$ \\
\hline
\end{tabular}

Table 3: Comorbidities in patients with pleural effusion $(N=100)$

\begin{tabular}{|l|c|c|c|c|c|}
\hline \multicolumn{1}{|c|}{ Diagnosis } & COPD f(\%) & DM f(\%) & HTN f(\%) & IHD f(\%) & Others f(\%) \\
\hline Tuberculosis & $17(28.8)$ & $10(16.9)$ & $2(3.3)$ & $3(5.0)$ & $2(3.3)$ \\
\hline Malignancy & $6(42.8)$ & $3(21.4)$ & 0 & 0 & 0 \\
\hline Pneumonia & $6(42.8)$ & $1(7.1)$ & $1(7.1)$ & $3(21.4)$ & $3(21.4)$ \\
\hline Congestive cardiac failure & $1(10)$ & $2(20)$ & 0 & $9(90)$ & $4(40)$ \\
\hline Liver disease & 0 & 0 & 0 & 0 & $3(100)$ \\
\hline
\end{tabular}

$\mathrm{COPD}=$ chronic obstructive pulmonary disease, $\mathrm{DM}=$ diabetes mellitus, $\mathrm{HTN}=$ hypertension, $\mathrm{IHD}=$ ischemic heart disease 
$>0.5$ was described as one of the criteria for diagnosis of exudative pleural effusion. ${ }^{16}$ We identified that mean level of pleural fluid to serum protein ratio was higher in patients with tubercular effusion as compared to non-tubercular effusion.

Most tubercular pleural effusions, unlike pulmonary tuberculosis present as an acute illness. Cough (93.8\%), temperature above $100^{\circ} \mathrm{F}(85.7 \%)$ and chest pain $(77.5 \%)$ are the three major presenting complaints in patient with tuberculous pleurisy. ${ }^{17} \mathrm{In}$ patients with human immunodeficiency virus (HIV) infection there is increased incidence of development of tuberculous pleural effusion as compared to the immune competent individuals. ${ }^{18,19}$ Presence of $\mathrm{DM}$ also increases the risk of active tuberculosis. ${ }^{20}$ Similarly, COPD patients have a threefold increased hazard ratio of developing active tuberculosis that is mainly dependent on an increased risk of pulmonary TB. ${ }^{21}$ We identified the presence of COPD in $28.8 \%$ and DM in $16.9 \%$ of patients with tubercular pleural effusion. None of the patients in our study had HIV infection. A prospective study in 2006 has identified the presence of pulmonary tuberculosis in $31 \%$ of patients with tuberculous pleuritis by analysis of

\section{REFERENCES:}

1. Dye C. Global epidemiology of tuberculosis. Lancet 2006; 367: 938-40.

2. Chetty KG. Transudative pleural effusions. Clin Chest Med 1985; 6: 49-54.

3. Light RW. Diagnostic principles in pleural disease. Eur Respir J 1997; 10: 476-81.

4. Storey DD, Dines DE, Coles DT. Pleural effusion: a diagnostic dilemma. J Am Med Assoc 1976; 236: 2183-6.

5. Gannels JJ. Perplexing pleural effusion. Chest 1978; 47: 390-3.

6. Keshmiri M, Hashemzadeh M. Use of cholesterol in differentiating of exudative and transudative pleural effusions. Med J Islamic Republic Ir 1997; 2: 187-9.

7. Khan FY, Alsamawi M, Yasin M et al. Etiology of pleural effusion among adults in the State of Qatar: a 1-year hospitalbased study. East Mediterr Health J 2011; 7: 611-8.

8. Heidari B, Bijani K, Eissazadeh M, Heidari P. Exudative pleural effusion: effectiveness of pleural fluid analysis and pleural biopsy. East Mediterr Health J 2007; 13: 765-73.

9. Liam CK, Lim KH, Wong CM. Causes of pleural exudates in a region with a high incidence of tuberculosis. Respirol 2000; 5: 33-8.

10. Valdes L, Alvarez D, Valle JM, Pose A, San Jose E. The etiology of pleural effusions in an area with high incidence of tuberculosis. Chest 1996; 109: 158-62.

11. Kalaajieh WK. E_ ology of exudative pleural effusions in adults in North Lebanon. Can Respir J 2001; 8: 93-7.

12. Pettersson T, Riska H. Diagnostic value of total and differential leukocyte counts in pleural effusions. Acta Med sputum and bronchial washings. ${ }^{22}$ We found that only $4(6.7 \%)$ patients of tubercular pleural effusion were sputum positive for tuberculosis.

This study has a few limitations. This is a single center retrospective study in limited number of patients and an analysis of the serum and pleural fluid lactate dehydrogenase were not performed.

\section{CONCLUSION:}

This retrospective study provides data on the causes of pleural effusion in patients of rural Nepal. It emphasizes that tuberculosis is the most important cause of pleural effusion in this area and should be considered in any adult patient with unilateral pleural effusion.

\section{Abbreviation:}

AST $=$ Aspartate amino transferase

ALT $=$ Alanine amino transferase

TLC $=$ total leukocyte count

$\mathrm{ADA}=$ adenosine deaminase

COPD $=$ chronic obstructive pulmonary disease

$\mathrm{DM}=$ diabetes mellitus

$\mathrm{HTN}=$ hypertension

$\mathrm{IHD}=$ ischemic heart disease
Scand 1981; 210: 129-35.

13. Light RW, Erozan YS, Ball WC Jr. Cells in pleural fluid: their value in differential diagnosis. Arch Intern Med 1973; 132: 854-60.

14. Verma SK, Dubey AL, Singh PA, Tewerson SL, Sharma D. Adenosine deaminase (ADA) level in tubercular pleural effusion. Lung India 2008; 25: 109-10.

15. Burgess LJ, Maritz FJ, Le Roux I, Taljaard JJ. Combined use of pleural adenosine deaminase with lymphocyte/ neutrophil ratio, increased specificity for the diagnosis of tuberculous pleuritis. Chest 1996; 109: 414-19.

16. Light RW, Macgregor MI, Luchsinger PC, Ball WC Jr. Pleural effusions: the diagnostic separation of transudates and exudates. Ann Intern Med 1972; 77: 507-13.

17. Berger HW, Mejia E. Tuberculous pleurisy. Chest 1973; 63: 88-92.

18. Batungwanayo J, Taelman H, Allen S, Bogaerts J, Kagame A, Van de Perre P. Pleural effusion, tuberculosis and HIV-1 infection in Kigali, Rwanda. AIDS 1993; 7: 73-9.

19. Light RW. Update on tuberculous pleural effusion. Respirol 2010; 15: 451-8.

20. Jeon CY, Murray MB. Diabetes Mellitus Increases the Risk of Active Tuberculosis: A Systematic Review of 13 Observational Studies. PLOS Med 2008; 5: e152.

21. Inghammar $M$, Ekbom $A$, Engstrom $G$ et al. COPD and the Risk of Tuberculosis - A Population-Based Cohort Study. PLOS ONE 2010; 5: e10138.

22. Kim H, Lee H, Kwon $\mathrm{S}$ et al. The prevalence of pulmonary parenchymal tuberculosis in patients with tuberculous pleuritis. Chest 2006; 129: 1253-8. 